\title{
Phase II trial of preoperative radiochemotherapy with concurrent bevacizumab, capecitabine and oxaliplatin in patients with locally advanced rectal cancer
}

Kathrin Dellas ${ }^{1,2^{*}}$, Thomas Höhler ${ }^{3}$, Thomas Reese ${ }^{4}$, Florian Würschmidt ${ }^{5}$, Erik Engel ${ }^{6}$, Claus Rödel $^{7}$, Wolfgang Wagner ${ }^{8}$, Michael Richter ${ }^{9}$, Dirk Arnold ${ }^{10}$ and Jürgen Dunst ${ }^{2}$

\begin{abstract}
Background: Preoperative radiochemotherapy (RCT) with 5-FU or capecitabine is the standard of care for patients with locally advanced rectal cancer (LARC). Preoperative RCT achieves pathological complete response rates ( $p C R$ ) of $10-15 \%$. We conducted a single arm phase II study to investigate the feasibility and efficacy of addition of bevacizumab and oxaliplatin to preoperative standard RCT with capecitabine.

Methods: Eligible patients had LARC (CT3-4; N0/1/2, M0/1) and were treated with preoperative RCT prior to planned surgery. Patients received conventionally fractionated radiotherapy (50.4 Gy in 1.8 Gy fractions) and simultaneous chemotherapy with capecitabine $825 \mathrm{mg} / \mathrm{m}^{2}$ bid $(\mathrm{d} 1-14, \mathrm{~d} 22-35)$ and oxaliplatin $50 \mathrm{mg} / \mathrm{m}^{2}(\mathrm{~d} 1, \mathrm{~d} 8$, $\mathrm{d} 22$, d29). Bevacizumab $5 \mathrm{mg} / \mathrm{kg}$ was added on days 1,15 , and 29. The primary study objective was the pCR rate.

Results: 70 patients with LARC (CT3-4; N0/1, MO/1), ECOG <2, were enrolled at 6 sites from 07/2008 through 02/ 2010 (median age 61 years [range 39-89], 68\% male). At initial diagnosis, 84\% of patients had clinical stage T3, 62\% of patients had nodal involvement and $83 \%$ of patients were M0. Mean tumor distance from anal verge was $5.92 \mathrm{~cm}$ ( \pm 3.68). 58 patients received the complete RCT (full dose RT and full dose of all chemotherapy). During preoperative treatment, grade 3 or 4 toxicities were experienced by 6 and 2 patients, respectively: grade 4 diarrhea and nausea in one patient (1.4\%), respectively, grade 3 diarrhea in 2 patients (3\%), grade 3 obstipation, anal abscess, anaphylactic reaction, leucopenia and neutropenia in one patient (1.4\%), respectively. In total, 30 patients (46\%) developed postoperative complications of any grade including one gastrointestinal perforation in one patient (2\%), wound-healing problems in 7 patients (11\%) and bleedings in 2 patients (3\%). pCR was observed in 12/69 (17.4\%) patients. Pathological downstaging (ypT $<\mathrm{cT}$ and $\mathrm{ypN} \leq \mathrm{cN}$ ) was achieved in 31 of 69 patients (44.9\%). All of the 66 operated patients had a R0 resection. 47 patients (68.1\%) underwent sphincter preserving surgery.
\end{abstract}

Conclusions: The addition of bevacizumab and oxaliplatin to RCT with capecitabine was well tolerated and did not increase perioperative morbidity or mortality. However, the $\mathrm{PCR}$ rate was not improved in comparison to other trials that used capecitabine or capecitabine/oxaliplatin in preoperative radiochemotherapy.

Keywords: Bevacizumab, Rectal cancer, Preoperative radiochemotherapy, Capecitabine, Oxaliplatin

\footnotetext{
* Correspondence: Kathrin.Dellas@uksh.de

${ }^{1}$ Department of Radiooncology, University of Kiel, Kiel, Germany

${ }^{2}$ Department of Radiooncology, University of Luebeck, Luebeck, Germany

Full list of author information is available at the end of the article
} 


\section{Introduction}

Preoperative radiochemotherapy (RCT) with 5-fluorouracil (5-FU) or capecitabine is the standard of care in many countries for patients with locally advanced rectal cancer (LARC) [1-4]. When followed by total mesorectal excision (TME), the risk of local relapse is $5-10 \%$ in patients treated with 5-fluorouracil (5-FU) and radiotherapy with 50.4 Gy. A pathological complete response (pCR) with these regimens is achieved in $10-15 \%$ of patients with acceptable toxicities. However, distant metastases occur in about a third of patients resulting in 10-year survival rates of $60 \%$ [5]. Therefore, there is a need to further improve treatment approaches to LARC.

A pCR after preoperative RCT is associated with favourable overall survival in rectal cancer patients and considered to be an appropriate early endpoint for evaluation of the effectiveness of intensified RCTregimens [6-14]. In four randomized phase III trials oxaliplatin was added to 5-FU based preoperative RCT, but results will require further discussion [15-18]. The German CAO/ARO/AIO-04 trial which added oxaliplatin to 5-FU showed a small but significant improvement in pCR rate (17\% vs. $13 \%)$. It has to be shown, whether these results further impact on decreased rates of local recurrences or distant metastases.

Bevacizumab (Avastin ${ }^{\circledR}$; Genentech, Inc., South San Francisco, CA, USA), is a humanized monoclonal antibody against vascular endothelial growth factor A (VEGF-A), a critical and essential factor of angiogenesis, that promotes new vessel formations in tumors $[19,20]$. In metastatic colorectal cancer, chemotherapy combined with bevacizumab improves progression free and overall survival in $1^{\text {st }}$ and $2^{\text {nd }}$ line treatment. Preclinical data suggest that incorporating bevacizumab into preoperative RCT might improve the efficacy of radiotherapy [21].

Bevacizumab is associated with mechanism-based adverse events, for example, hypertension, gastrointestinal perforation, serious bleeding, thromboembolic events and wound-healing complications. Trials reported an increased risk of complications across all tumor types, which might be related to the VEGF blocking mechanism raising the question if the anti-VEGF-containing regimen may increase wound complications in the preoperative setting [22].

We initiated this prospective trial to evaluate the efficacy, safety and tolerability of adding bevacizumab to preoperative radiotherapy with a regimen of concurrent capecitabine and oxaliplatin (BevXelOx-RT) in patients with LARC. The pCR rate was the primary endpoint of this phase II study.

\section{Patients and methods}

The study was conducted according to the principles of the Declaration of Helsinki and to good clinical practice guidelines. The Ethics Committee, University of Luebeck (No. 07-197) and all local review boards of the participating institutions approved this study. Each patient gave written informed consent before being accrued.

\section{Eligibility criteria}

The eligibility criteria included histopathologically confirmed rectal cancer with the inferior margin within $16 \mathrm{~cm}$ from the anal verge, $\mathrm{cT} 3-4$ disease and/or positive perirectal lymph nodes without evidence of synchronous metastatic disease; however, a single resectable liver metastasis was not an exclusion criterion. Staging required endorectal ultrasonography and computed tomography of the pelvis, whereas the use of magnetic resonance imaging for staging was encouraged. Further inclusion criteria included Eastern Cooperative Oncology Group performance status $<2$, adequate renal, hepatic and hematologic function (creatinine clearance $>50 \mathrm{~mL} / \mathrm{min}$, total bilirubin concentration $\leq 2.0 \mathrm{mg} / \mathrm{dL}$, liver transaminases and alkaline phosphatase concentration less than three times the upper normal limit and neutrophils $>2.5$ $\mathrm{x} 10^{9} / \mathrm{L}$ ). Patients were excluded if radiotherapy to the pelvic region or chemotherapy had previously been administered. Patients suffering from the following conditions were also ineligible: inflammatory bowel disease, malabsorption syndrome, history of other cancer, previous history of cardiac arrhythmia or coronary heart disease, peripheral neuropathy and psychiatric disorders or psychological disabilities thought to adversely affect treatment compliance. Pregnant or lactating patients and woman with childbearing potential who had lacked effective contraception were excluded.

\section{Pretreatment evaluation}

Pretreatment evaluation included a complete history and physical examination, biopsy, digital examination, rigid rectoscopy, colonoscopy, endorectal ultrasound, computed tomography of the pelvis and abdomen and chest X-ray, ECG. Complete laboratory tests included a full blood count, blood electrolytes, creatinine, urea, liver transaminases, alkaline phosphatase, total bilirubin.

\section{Radiotherapy}

Radiotherapy was delivered by a linear accelerator with a minimal energy of $6 \mathrm{MeV}$ through a three- or four-field box technique to the primary tumor and mesorectal, presacral and regional lymph nodes up to the level of the fifth lumbal vertebra. The anal sphincter complex was included for low-lying tumors $(<6 \mathrm{~cm}$ from the anal verge). The dose was prescribed to a reference point according to ICRU 50 with the $95 \%$ reference-isodose covering the planning target volume. All patients received a total dose of $50.4 \mathrm{~Gy}$, with daily fractions of 1.8 Gy on 5 days per week. 


\section{Bevacizumab and preoperative RCT}

During preoperative therapy, bevacizumab was administered with $5 \mathrm{mg} / \mathrm{kg}$ body weight on days 1,15 and 29 . Capecitabine was administered at a fixed dose of $825 \mathrm{mg} / \mathrm{m}^{2}$ twice daily (30 min after breakfast and dinner) on days 1 to 14 and 22 to 35 of radiotherapy, and oxaliplatin as a 2-h infusion on days 1, 8, 22 and 29 at a dose of $50 \mathrm{mg} / \mathrm{m}$, according to a schedule previously used in 2 phase II trials of our group [23-25] (Figure 1).

During treatment, patients were evaluated weekly regarding history, clinical examination, blood count, and biochemistry. Toxicities were assessed by National Cancer Institute Common Toxicity Criteria (NCI-CTC), version 3.0. We did not modify the radiotherapy schedule for grade $\leq 2$ toxicities unless the severity worsened. Image-guided re-evaluation of the primary tumor was performed four weeks after the completion of preoperative treatment.

\section{Surgery and pathology}

Four to six weeks after completion of radiochemotherapy with bevacizumab, TME was performed according to a standardized technique. If adjacent organs were involved intraoperatively, surgery was extended to partial or total resection of those adjacent pelvic organs. Central quality control of the surgery was not performed.

Pathologic complete response (pCR) was defined as the complete disappearance of viable tumor cells in the primary tumor and lymph nodes (ypT0N0). Histological regression was semiquantitatively determined according to a 5 -point regression grading system established by Dworak by the local pathologist (no centralized analysis) [26].

\section{Adjuvant chemotherapy}

Adjuvant chemotherapy was not mandatory by this protocol but it was recommended as monotherapy with capecitabine $1250 \mathrm{mg} / \mathrm{m}^{2}$ twice daily on days 1 to 14 , repetition from day 22 for a total of 4 cycles.

\section{Study design, endpoints and statistical analysis}

A prospective single-stage design according to Fleming was selected. The primary endpoint of the phase II study after preoperative BevXelOx-RT was pCR rate. Data of phase II trials with capecitabine, oxaliplatin and radiotherapy suggests pCR rates of $15-20 \%$. We aimed to evaluate whether a $25 \%$ pCR rate could be achieved by adding bevacizumab to standard preoperative radiochemotherapy. A pCR rate of $\leq 15 \%$ was considered futile. With a sample size of 70 patients, the risk of erroneously claiming a major increase in activity despite a true pCR rate $\leq 15 \%$ (type I error) amounted to $10 \%$, with a type II error probability of mistakenly rejecting BevXelOx-RT in the case of truly promising activity set of $20 \%$ corresponding to a power of $80 \%$ in a one-sided chi-square test. The secondary endpoints included radiographic response, pathologic downstaging, tumor regression grading, rates of sphincter-sparing surgery, toxicity (particularly postoperative surgical complications, risk of bowel perforation, wound healing complications and bleeding), rates of R0 resection and feasibility.

\section{Results}

\section{Patient characteristics}

A total of 70 patients were enrolled into the study at 6 investigation centers from July 2008 through February

Histopathologically confirmed rectal cancer

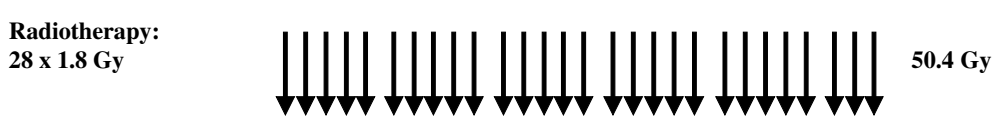

Chemotherapy:

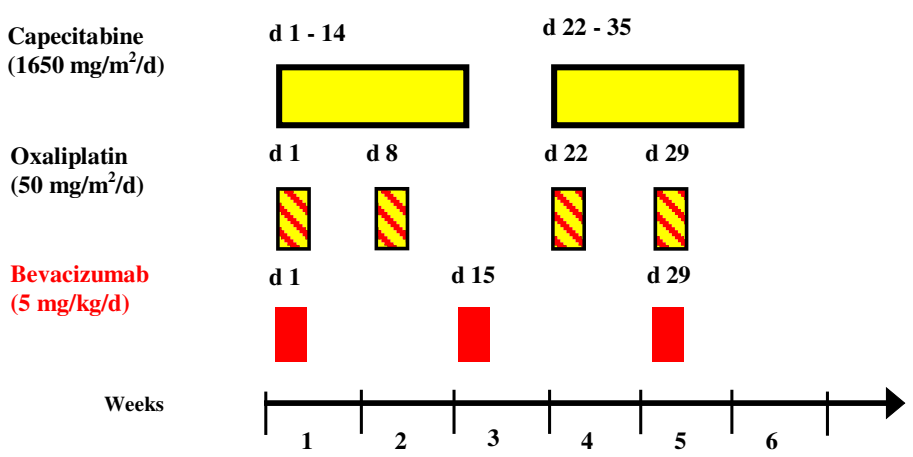

Figure 1 Overview of the study design and treatment schedule. 
2010. One patient was ineligible and excluded from the analysis because of serious uncontrolled physical or psychological disabilities. Therefore the intent-to-treat population is based on 69 patients. For 4 of these patients, the primary endpoint was not evaluated. The per-protocol -population consisted of 58 patients, who received the complete RCT. Safety analyses were performed within the 69 patients of the safety-population receiving at least on treatment application of the RCT. ITT- and safety population were not different from composition. The median age was 61 years (range 39-89), at initial diagnosis of the locally advanced rectal cancer $84 \%$ of patients showed clinical stage T3, $62 \%$ of patients had nodal involvement and $83 \%$ of patients were M0. The patient characteristics are listed in Table 1.

\section{Toxicity and dose modification}

A total of 58 patients received preoperative BevXelOx-RT at the recommended dose level. Tables 2 and 3 show the frequencies and grades of the treatment-related toxicity.

Table 1 Baseline characteristics $(n=69)$

\begin{tabular}{|c|c|}
\hline Characteristics & Value \\
\hline \multicolumn{2}{|l|}{ Age, years } \\
\hline Median age & 61.0 \\
\hline Range & $39-89$ \\
\hline \multicolumn{2}{|l|}{ Gender, n (\%) } \\
\hline Male & $47(68)$ \\
\hline Female & $22(32)$ \\
\hline \multicolumn{2}{|c|}{ ECOG performance status, $\mathrm{n}(\%)$} \\
\hline 0 & $47(78)$ \\
\hline 1 & $13(22)$ \\
\hline \multicolumn{2}{|l|}{ TN clinical stage, n (\%) } \\
\hline T2N1-N2 & $2(3)$ \\
\hline T3NO & $12(17)$ \\
\hline T3N1-N2 & $44(64)$ \\
\hline T4NO & $3(4)$ \\
\hline T4N1-N2 & $4(6)$ \\
\hline \multicolumn{2}{|l|}{ M clinical stage, $n(\%)$} \\
\hline Mx & $10(14)$ \\
\hline Mo & $57(83)$ \\
\hline M1 & $2(3)$ \\
\hline \multicolumn{2}{|c|}{ Tumor distance from anal verge, $\mathrm{n}(\%)$} \\
\hline Mean \pm SD $(\mathrm{cm})$ & $5.92 \pm 3.68$ \\
\hline Upper third $(\geq 12 \mathrm{~cm})$ & $20(33)$ \\
\hline Middle third $(6-12 \mathrm{~cm})$ & $26(42)$ \\
\hline Lower third $(\leq 6 \mathrm{~cm})$ & $27(43)$ \\
\hline
\end{tabular}

Abbreviation: ECOG = Eastern Cooperative Oncology Group. Data presented as number of patients, with percentages in parentheses.
Table 2 Acute toxicities occurring during preoperative treatment

\begin{tabular}{lcccc}
\hline Toxicities & \multicolumn{5}{c}{ Patients, n (\%) } \\
\cline { 2 - 5 } Hematological & Grade 1 & Grade 2 & Grade 2 & Grade 2 \\
Anemia & $2(3)$ & $1(1)$ & - & - \\
Leucopenia & $7(10)$ & $5(7)$ & $1(1)$ & - \\
Thrombocytopenia & $3(4)$ & $1(1)$ & - & - \\
Non-hematological & & & & \\
Diarrhea & $17(25)$ & $8(12)$ & $2(3)$ & $1(1)$ \\
Nausea & $17(25)$ & $5(7)$ & - & $1(1)$ \\
Fatigue & $15(22)$ & $2(3)$ & - & - \\
Paresthesia & $13(19)$ & $2(3)$ & - & - \\
Obstipation & $2(3)$ & - & $1(1)$ & - \\
Anal abscess & - & - & $1(1)$ & - \\
Anaphylactic reaction & - & - & $1(1)$ & - \\
Hypertension & - & $5(7)$ & - & - \\
Palmar-plantar & $8(12)$ & - & - & - \\
erythrodysesthesia & & & & - \\
Pain & $5(7)$ & $2(3)$ & - & - \\
\hline
\end{tabular}

Adverse events were grouped whether they occured preoperatively and postoperatively. For both periods, 17 and 18 severe adverse events were reported, respectively. No perioperative death was documented.

The most frequent adverse event reported in the period up to one week after radiotherapy was in 31 patients

Table 3 Postoperative acute toxicities

\begin{tabular}{lcccc}
\hline Toxicities & \multicolumn{4}{c}{ Patients, $\mathbf{n}(\%)$} \\
\cline { 2 - 5 } Hematological & Grade 1 & Grade 2 & Grade 3 & Grade 4 \\
Leucopenia & $2(3)$ & $1(1)$ & $1(1)$ & - \\
Non-hematological & & & & \\
Palmar-plantar & $14(20)$ & $2(3)$ & $1(1)$ & - \\
erythrodysesthesia & $11(16)$ & $2(3)$ & $1(1)$ & - \\
Fatigue & $6(9)$ & $2(3)$ & $3(4)$ & - \\
Diarrhea & $5(7)$ & $5(7)$ & - & - \\
Paresthesia & - & - & - & $1(1)$ \\
Ileus & $2(3)$ & $1(1)$ & $1(1)$ & - \\
Nausea & - & - & $1(1)$ & - \\
Proctitis & - & - & $1(1)$ & - \\
Abdominal pain & - & - & $1(1)$ & - \\
Anal fistula & - & - & $1(1)$ & - \\
Pelvic abscess & $1(1)$ & $4(6)$ & $1(1)$ & - \\
Sensory neuropathy & - & - & $1(1)$ & - \\
Somnolence & - & - & $1(1)$ & - \\
Delayed woundhealing & & & & \\
\hline
\end{tabular}


(45\%), of whom of 3 (4\%) experienced grade 3 or 4 diarrhea, followed by nausea in $22(32 \%)$ of patients, fatigue in 17 (32\%), paresthesia in 15 (22\%) and leucopenia in 13 (19\%) patients. Any grade 3 or 4 toxicities were experienced by 6 and 2 patients, respectively: grade 4 toxicities included diarrhea and nausea and were restricted in one patient (1.4\%), respectively. Grade 3 diarrhea occurred in 2 patients (3\%) and grade 3 obstipation, anal abscess, anaphylactic reaction, leucopenia and neutropenia occurred in one patient (1.4\%), respectively (Table 2 ).

The postoperative period was defined as the interval between surgery and the final examination four weeks after surgery. During this period, 43 (27\%) adverse events occurred in 26 patients within the gastrointestinal tract system. The most common adverse event was the palmarplantar erythrodysesthesia in 17 (25\%) patients followed by fatigue in $14(20 \%)$, diarrhea in $11(16 \%)$ and paresthesia in $10(14 \%)$ patients. The only grade 4 toxicity was ileus in one patient. Grade 3 toxicity occurred in 10 patients: diarrhea in 3 patients (4\%) and nausea, proctitis, abdominal pain, anal fistula, pelvic abscess, sensoric neuropathy, somnolence, palmar-plantar erythrodysesthesia, fatigue, pain, delayed woundhealing and leucopenia in one patient (1.4\%), respectively. Furthermore, we observed thrombosis in 3 patients (4\%) and one deep vein thrombosis in one patient (1.4\%) without stating grade (Table 3 ).

Among 69 patients commencing treatment, dose reduction or treatment discontinuations was necessary in 11 patients. 3 patients did not proceed to surgery (one patient with lost of follow up before surgery, one patient with progressive disease during preoperative treatment and exclusion from the study due to the protocol, one patient refused surgery), for one additional patient the pathological review was not assessable. For these 4 patients, the primary endpoint was not evaluated. In 9 patients, interruption of therapy was observed.

The mean relative dose intensity was high for bevacizumab (98.6\%), oxaliplatin (97.8\%) and radiotherapy (98.4\%). For capecitabine being administered at a fixed dose of $825 \mathrm{mg} / \mathrm{m}^{2}$ twice daily on days 1 to 14 and 22 to 35 - according to the flat dosing scheme patients received $2000 \mathrm{mg} / \mathrm{m}^{2}$ to $3000 \mathrm{mg} / \mathrm{m}^{2}$. 62 of 69 patients $(90 \%)$ received $100 \%$ of the recommended capecitabine, with dose reduction of capecitabine being observed in 7 patients.

\section{Efficacy}

66 of 69 patients underwent surgery and achieved R0-resection (95.7\%, Table 4). A pCR defined as ypT0N0 was observed in 12 of 69 patients for the intent-to-treat population (17.4\%; 95\% confidence interval, 10.4\%26.6\%). Pathological downstaging (ypT $<\mathrm{cT}$ and $\mathrm{ypN} \leq$ $\mathrm{cN}$ ) was noted in 31 patients (44.9\%, Table 5).

Pathohistology information was available in 56 out of 66 patients (on treatment cohort). For 10 patients
Table 4 Surgical procedures and resection status after preoperative BevXelOx-RT

\begin{tabular}{ll}
\hline Characteristics & Value \\
\hline Type of surgery, $\mathrm{n}(\%)$ & 28 \\
Low anterior resection & 19 \\
Abdominoperineal exstirpation & 13 \\
Total mesorectal excision & 1 \\
Partial mesorectal excision & 1 \\
Mesorectal excision & 1 \\
Laparoscopic assisted rectal resection & 1 \\
Rectal exstirpation & 1 \\
Sigma-rectal exstirpation & 1 \\
Rectal resection with pouch &
\end{tabular}

RO

$66(95.7)$

Data presented as number of patients, with percentages in parentheses.

${ }^{\S}$ Refers to the primary tumor, 66 of 69 patients who underwent surgery.

adequate data were not assessable. A complete regression of the tumor defined as ypT0 was documented in 11 patients (15.9\% of the ITT cohort; $90 \%$ confidence interval, 9.2\%-25.0\%; $19.6 \%$ of the treatment cohort). 22 more patients $(31.9 \%$ and $39.2 \%$ of the ITT cohort and on treatment cohort, respectively) showed good tumor regression ( $>50 \%$ of the tumor mass), moderate $(n=15$, $21.7 \%)$, or minimal $(\mathrm{n}=8,11.6 \%)$ tumor regression, whereas no pathohistological response was observed in 3 patients (4.3\%).

39 patients (56.6\%) had no evidence for nodal involvement defined as pN0, 4 patients $(5.8 \%)$ showed a good nodal regression, moderate $(\mathrm{n}=2,2.8 \%)$, minimal $(\mathrm{n}=1$, $1.4 \%)$ and no regression was noted in 4 patients (5.8\%).

The sphincter preserving rate was $68.1 \%$ (47 of 69 patients). A temporary stoma was used in 13 patients (19.7\%). In total, 25 patients (36.2\%) developed postoperative complications of any grade including one gastrointestinal perforation in one patient (1.4\%), wound-healing problems in 7 patients $(9.8 \%)$ and bleedings in 2 patients $(2.8 \%)$.

Follow up evaluation was limited to 6 months after initiation. Disease progression occurred in four patients. Two patients developed distant metastases (one lung, one liver) two months after initiation. For the third patient with progressive disease one month after initiation of therapy, adequate data regarding localization were not available. One patient with synchronous distant metastases (liver, lymph nodes) achieved tumor response (partial remission) with incomplete information of local lesion. 6 months after initiation all patients were alive.

\section{Discussion}

We conducted this phase II trial as a multimodal regimen for patients with locally advanced rectal cancer, 
Table 5 Postoperative pathological TNM stages compared with pretreatment clinical stages $(n=69)$

\begin{tabular}{|c|c|c|c|c|c|c|c|c|c|c|c|}
\hline \multirow[b]{2}{*}{ Baseline stage } & \multicolumn{11}{|c|}{ Pathologic stage } \\
\hline & ypTis & урто & урT1 & урт2 & урт3 & урT4 & ypTmissing & ypNO & ypN1 & yPN2 & ypNmissing \\
\hline $\mathrm{T} 1(\mathrm{n}=1)$ & & & & & 1 & & & & & & \\
\hline$T 2(n=3)$ & & & & 2 & 1 & & & & & & \\
\hline T3 $(n=57)$ & 1 & 12 & 3 & 14 & 24 & 2 & 1 & & & & \\
\hline$T 4(n=5)$ & & & & 1 & 2 & 2 & & & & & \\
\hline No $(n=15)$ & & & & & & & & 13 & 1 & 1 & \\
\hline$N 1(n=41)$ & & & & & & & & 28 & 6 & 6 & 1 \\
\hline N2 $(n=8)$ & & & & & & & & 5 & 2 & 1 & \\
\hline$N x(n=2)$ & & & & & & & & 1 & & 1 & \\
\hline
\end{tabular}

consisting of radiotherapy with concurrently administered chemotherapy with capecitabine, oxaliplatin and bevacizumab. This report summarizes the results of 69 patients and to the best of our knowledge, this is the largest trial in the multimodality therapy with bevacizumabcontaining radiochemotherapy of rectal cancer patients in the preoperative setting.

Regarding the primary endpoint of our phase II study, we failed to demonstrate a pCR rate considered to be "interesting". The pCR rate of less than $18 \%$ was in the range of other reports investigating regimen with capecitabine alone or plus oxaliplatin in preoperative radiochemotherapy. Pathological downstaging (yp $<<\mathrm{cT}$ and $y p N \leq \mathrm{cN}$ ) was observed in 31 of 69 patients (44.9\%).

Bevacizumab containing preoperative radiochemotherapy in rectal cancer has been investigated in a number of trials and appears to be safe and feasible with beneficial effects on vascular normalization, and promising response rates in smaller studies [27-33]. Velenik et al. [27] recently reported the efficacy of the addition of bevacizumab to capecitabine-RT in 61 patients with LARC. In this investigation, $13.3 \%$ achieved a pCR, and $\mathrm{T}-, \mathrm{N}$ - and overall downstaging rates were $46.7 \%, 65.0 \%$ and $75.0 \%$, respectively. Kennecke et al. [28] reported a similar pCR rate of $18.4 \%$ after a further triple treatment with bevacizumab, capecitabine, oxaliplatin and radiation. In 9 patients $(23.7 \%)$ a complete regression of the tumor (ypT0) was documented including two patients with nodal metastases. Similarly, five of 25 patients (20\%) had a pCR in the trial conducted by Dipetrillo et al. [29] using bevacizumab, oxaliplatin, 5-fluorouracil and radiation for rectal cancer. However, in this small study two cycles of induction mFOLFOX6 and bevacizumab were administered before concurrent bevacizumab, oxaliplatin, continuous infusion 5-fluoruracil and radiation.

Several phase II and III trials have shown that the combination of preoperative radiation with 5-FU/capecitabine and oxaliplatin shows moderately high rates of histopathological eradication of the tumor. Data of phase II trials suggested a pCR rate up to $20 \%$, whereas results of phase
III trials showed either no or only modest improvements with respect to the pCR rates [15-18,34,35]: the Italian STAR-01 study [16] as well as the US NSABP R-04 trial [17] and the French ACCORD study [18] did not show a significant increased rate of $\mathrm{pCR}$ 's, and in the German phase III trial, a small but statistically significant increment was documented [15].

The potential role of preoperative bevacizumab in combination with oxaliplatin remains still unclear. Preoperative bevacizumab could potentially impact the histopathological eradication alone or in combination with 5-FU or capecitabine since unprecedented synergistic or additive interaction between antiangiogenic and cytotoxic therapies initially has been reported in preclinical settings as well as in early phase I/II trials in terms of administration of bevacizumab alone or combined with 5-FU [21].

The addition of bevacizumab to radiochemotherapy with capecitabine and oxaliplatin did not lead to increased perioperative morbidity or mortality. The observed complications regarding quantity and kind of intervention after surgical treatment were within the expected range, without evidence of a modified spectrum of complications. In particular, we did not observe an increased number of bleeding complications, perioperative complications including anastomotic insufficiency or thromboembolic events. The most frequent adverse events reported in the period of BevXelOx-RT were chemotherapy-related, as diarrhea, nausea, fatigue, and paresthesia. In the postoperative period including surgery adverse events were mainly related to gastrointestinal tract system but also to pelvic abscess and delayed wound healing. No treatment related death was observed. With regard to perioperative complications in published bevacizumab-containing approaches in rectal cancer $[29,30,32]$ we can conclude that bevacizumab does not increase the perioperative complication rate.

Potential benefits of bevacizumab may result in two different ways: to improve local control rate, which may be mirrored by the increased pathohistological response, 
and to prevent systemic metastases. However, as shown in this single arm phase II trial, the addition of bevacizumab to a complex multimodal regimen of a combination chemotherapy regimen and conventionally fractionated radiotherapy did not result in a clinically relevant increased pathohistologic response (namely $\mathrm{pCR}$ rate) compared to other reports. However, this somehow stands in contrast to the benefit of bevacizumab added to similar chemotherapy (FOLFOX or XELOX) regimens in metastatic colorectal cancer, when used as neoadjuvant therapy for liver metastases: Here, four phase II trials including more than 300 patients have reported higher pathohistologic response, including $\mathrm{pCR}$ rates [36-39]. Interestingly, the potential benefit of adding bevacizumab to standard chemotherapy was also seen in breast cancer, where even randomized trials reported increased pathologic complete response rates by more than $6 \%(34.5 \%$ vs. $28.2 \%)$ and overall clinical complete response rates by up to $8 \%(87.4 \%$ vs. $79.6 \%)[40,41]$.

It is not understood why this effect was not observed here; despite the preclinical and early clinical findings that bevacizumab may impact the pCR trials in terms of administration as monotherapy or in combination with fluoropyrimidines alone [21]. The potential benefit of adding bevacizumab to FOLFOX or XELOX in order to prevent patients with LARC from distant failure is questionable since bevacizumab in combination with oxaliplatin-based adjuvant therapy in patients with resected stage III or high-risk stage II colon carcinoma did not result in a clinical benefit $[42,43]$.

Long term effects of this combined therapy regimen can not be judged by this trial and we also recognize the still ongoing discussion regarding the problem of using pCR as surrogate parameter in rectal cancer. Stage, tumor specimen, quality of pathologic analysis and the time period between therapy and surgery are considered to be key criterion for the impact on pCR. Several trials chosing $\mathrm{pCR}$ as a primary endpoint achieved lower rates of complete responses compared with historical data resulting from quality improvement of pathohistologic analysis [44]. The randomized phase II trial of Dewdney et al. demonstrated in KRAS/BRAF wild-type rectal cancer patients a significantly improved overall survival of the cetuximab arm without an increase of the pCR rate suggesting a possible benefit from systemic approaches before local therapy based on some not yet clearly understood biologic activity in this setting [44]. These effects regarding the long-term outcomes may also arise in the actual investigation.

However, at this time, long-term follow up results on survival and also on local control after preoperative radiochemotherapy with bevacizumab are needed in order to determine the potential impact of adding bevacizumab to preoperative standard treatment in patients with locally advanced rectal cancer. Furthermore, randomized trials are ongoing, in order to investigate the benefit of bevacizumab in addition to chemotherapy alone (without radiotherapy) in LARC.

\section{Conclusion}

The results of our present clinical trial confirm that preoperative bevacizumab-based radiochemotherapy is feasible and well tolerated in LARC. However, the incorporation of bevacizumab into a combination regimen with 5-FU and oxaliplatin seems not to increase pathohistological response rates.

\section{Competing interests}

This was an investigator-initiated trial supported in part by a grant from Hoffmann-La Roche GmbH, Darmstadt, Germany.

K. Dellas received speakers honoraria from Hoffmann-La Roche AG, Grenzach Whylen, Germany; C. Rödel received research funds from Hoffmann-La Roche AG, Grenzach Whylen, Germany and Merck Serono GmbH, Darmstadt, Germany and speakers honoraria from Merck Serono GmbH, Darmstadt, Germany; D. Arnold received research funds and speakers honoraria from Hoffmann-La Roche AG, Grenzach Whylen, Germany and Sanofi-Aventis Pharma GmbH, Berlin, Germany; J. Dunst received research funds and speakers honoraria from Hoffmann-La Roche AG, Grenzach Whylen, Germany.

\section{Authors' contributions}

$\mathrm{KD}, \mathrm{CR}, \mathrm{MR}, \mathrm{DA}$ and JD contribution to design and supervision of the study. $K D, T H, T R, F W, E E, C R, W W, D A$ and JD contribution to therapy and acquisition of data. MR contribution to acquisition of data and analysis. KD, $C R, M R, D A$ and JD contribution to interpretation of data. KD drafted and reviewed the manuscript and all authors edited and approved the final version.

\section{Author details}

'Department of Radiooncology, University of Kiel, Kiel, Germany.

${ }^{2}$ Department of Radiooncology, University of Luebeck, Luebeck, Germany. ${ }^{3}$ Prosper Hospital Recklinghausen, Recklinghausen, Germany. ${ }^{4}$ Martin Luther University Halle-Wittenberg, Department of Radiotherapy, Halle, Saale, Germany. ${ }^{5}$ Private Practice of Radiooncology, Radiologische Allianz, Hamburg, Germany. ${ }^{6}$ Private Practice of Hematology and Medical Oncology, Hamburg, Germany. ${ }^{7}$ University of Frankfurt, Department of Radiooncology, Frankfurt, Germany. ${ }^{8}$ Department of Radiooncology, Osnabrueck, Germany. ${ }^{9}$ Coordination Center for Clinical Trials, Halle, Saale, Germany. ${ }^{10}$ Clinic for Medical Oncology, Tumor Biology Center Freiburg, Freiburg, Germany.

Received: 29 December 2012 Accepted: 1 April 2013

Published: 15 April 2013

\section{References}

1. Hofheinz RD, Wenz F, Post S, Matzdorff A, Laechelt S, Hartmann JT, Müller L, Link H, Moehler M, Kettner E, Fritz E, Hieber U, Lindemann HW, Grunewald M, Kremers S, Constantin C, Hipp M, Hartung G, Gencer D, Kienle P, Burkholder I, Hochhaus A: Chemoradiotherapy with capecitabine versus fluorouracil for locally advanced rectal cancer: a randomised, multicentre, non-inferiority, phase 3 trial. Lancet Oncol 2012, 13(6):579-588.

2. Bosset JF, Collette L, Calais G, Mineur L, Maingon P, Radosevic-Jelic L, Daban A, Bardet E, Beny A, Ollier JC: EORTC Radiotherapy Group Trial 22921, Chemotherapy with preoperative radiotherapy in rectal cancer. $N$ Engl J Med 2006, 355(11):1114-1123.

3. Gérard JP, Conroy T, Bonnetain F, Bouché O, Chapet O, Closon-Dejardin MT, Untereiner M, Leduc B, Francois E, Maurel J, Seitz JF, Buecher B, Mackiewicz $R$, Ducreux M, Bedenne L: Preoperative radiotherapy with or without concurrent fluorouracil and leucovorin in T3-4 rectal cancers: results of FFCD 9203. J Clin Oncol 2006, 24(28):4620-4625.

4. Sauer R, Becker H, Hohenberger W, Rödel C, Wittekind C, Fietkau R, Martus P, Tschmelitsch J, Hager E, Hess CF, Karstens JH, Liersch T, Schmidberger H, Raab R: German Rectal Cancer Study Group, Preoperative versus 
postoperative chemoradiotherapy for rectal cancer. N Engl J Med 2004, 351(17):1731-1740.

5. Sauer R, Liersch T, Merkel S, Fietkau R, Hohenberger W, Hess C, Becker H, Raab HR, Villanueva MT, Witzigmann H, Wittekind C, Beissbarth T, Rödel C: Preoperative Versus Postoperative Chemoradiotherapy for Locally Advanced Rectal Cancer: Results of the German CAO/ARO/AIO-94 Randomized Phase III Trial After a Median Follow-Up of 11 Years. J Clin Oncol 2012, 30(16):1926-1933.

6. Valentini V, van Stiphout RG, Lammering G, Gambacorta MA, Barba MC, Bebenek M, Bonnetain F, Bosset JF, Bujko K, Cionini L, Gerard JP, Rödel C, Sainato A, Sauer R, Minsky BD, Collette L, Lambin P: Nomograms for predicting local recurrence, distant metastases, and overall survival for patients with locally advanced rectal cancer on the basis of European randomized clinical trials. J Clin Oncol 2011, 29(23):3163-3172.

7. Maas M, Nelemans PJ, Valentini V, Das P, Rödel C, Kuo LJ, Calvo FA, GarcíaAguilar J, Glynne-Jones R, Haustermans K, Mohiuddin M, Pucciarelli S, Small W Jr, Suárez J, Theodoropoulos G, Biondo S, Beets-Tan RG, Beets GL: Longterm outcome in patients with a pathological complete response after chemoradiation for rectal cancer: a pooled analysis of individual patient data. Lancet Oncol 2010, 11(9):835-844.

8. Smith N, Brown G: Preoperative staging of rectal cancer. Acta Oncol 2008, 47(1):20-31.

9. Rödel C, Martus P, Papadoupolos T, Füzesi L, Klimpfinger M, Fietkau R, Liersch T, Hohenberger W, Raab R, Sauer R, Wittekind C: Prognostic significance of tumor regression after preoperative chemoradiotherapy for rectal cancer. J Clin Oncol 2005, 23(34):8688-8696.

10. Vecchio FM, Valentini V, Minsky BD, Padula GD, Venkatraman ES, Balducci M, Miccichè F, Ricci R, Morganti AG, Gambacorta MA, Maurizi F, Coco C: The relationship of pathologic tumor regression grade (TRG) and outcomes after preoperative therapy in rectal cancer. Int J Radiat Oncol Biol Phys 2005, 62(3):752-760.

11. Guillem JG, Chessin DB, Cohen AM, Shia J, Mazumdar M, Enker W, Paty PB, Weiser MR, Klimstra D, Saltz L, Minsky BD, Wong WD: Long-term oncologic outcome following preoperative combined modality therapy and total mesorectal excision of locally advanced rectal cancer. Ann Surg 2005, 241(5):829-836.

12. Gunderson LL, Sargent DJ, Tepper JE, Wolmark N, O'Connell MJ, Begovic M, Allmer C, Colangelo L, Smalley SR, Haller DG, Martenson JA, Mayer RJ, Rich TA, Ajani JA, MacDonald JS, Willett CG, Goldberg RM: Impact of T and N stage and treatment on survival and relapse in adjuvant rectal cancer: a pooled analysis. J Clin Oncol 2004, 22(10):1785-1796.

13. García-Aguilar J, Hernandez De Anda E, Sirivongs P, Lee SH, Madoff RD, Rothenberger DA: A pathologic complete response to preoperative chemoradiation is associated with lower local recurrence and improved survival in rectal cancer patients treated by mesorectal excision. Dis Colon Rectum 2003, 46(3):298-304.

14. Janjan NA, Crane C, Feig BW, Cleary K, Dubrow R, Curley S, Vauthey JN, Lynch P, Ellis LM, Wolff R, Lenzi R, Abbruzzese J, Pazdur R, Hoff PM, Allen P, Brown T, Skibber J: Improved overall survival among responders to preoperative chemoradiation for locally advanced rectal cancer. Am J Clin Oncol 2001, 24(2):107-112.

15. Rödel C, Liersch T, Becker H, Fietkau R, Hohenberger W, Hothorn T, Graeven U, Arnold D, Lang-Welzenbach M, Raab HR, Sülberg H, Wittekind C, Potapov S, Staib L, Hess C, Weigang-Köhler K, Grabenbauer GG, Hoffmanns H, Lindemann F, Schlenska-Lange A, Folprecht G, Sauer R, on behalf of the German Rectal Cancer Study Group: Preoperative chemoradiotherapy and postoperative chemotherapy with fluorouracil and oxaliplatin versus fluorouracil alone in locally advanced rectal cancer: initial results of the German CAO/ARO/ AlO-04 randomised phase 3 trial. Lancet Oncol 2012, 13(7):679-687.

16. Aschele C, Cionini L, Lonardi S, Pinto C, Cordio S, Rosati G, Artale S, Tagliagambe A, Ambrosini G, Rosetti P, Bonetti A, Negru ME, Tronconi MC, Luppi G, Silvano G, Corsi DC, Bochicchio AM, Chiaulon G, Gallo M, Boni L: Primary tumor response to preoperative chemoradiation with or without oxaliplatin in locally advanced rectal cancer: pathologic results of the STAR-01 randomized phase III trial. J Clin Oncol 2011, 29(20):2773-2780.

17. Roh MS, Yothers GA, O'Connell MJ, Beart RW, Pitot HC, Shields AF, Parda DS, Sharif S, Allegra CJ, Petrelli NJ, Landry JC, Ryan DP, Arora A, Evans TL, Soori GS, Chu L, Landes RV, Mohiuddin M, Lopa S, Wolmark N: The impact of capecitabine and oxaliplatin in the preoperative multimodality treatment in patients with carcinoma of the rectum: NSABP R-04. J Clin Oncol 2011, 29:suppl 15; abstr 3503.
18. Gérard JP, Azria D, Gourgou-Bourgade S, Martel-Laffay I, Hennequin C, Etienne PL, Vendrely V, François $E$, de La Roche G, Bouché O, Mirabel X, Denis B, Mineur L, Berdah JF, Mahé MA, Bécouarn Y, Dupuis O, Lledo G, Montoto-Grillot C, Conroy T: Comparison of two neoadjuvant chemoradiotherapy regimens for locally advanced rectal cancer: results of the phase III trial ACCORD 12/0405-Prodige 2. J Clin Oncol 2010, 28(10): 1638-1644.

19. Ferrara $\mathrm{N}$ : Vascular endothelial growth factor as a target for anticancer therapy. Oncologist 2004, 9(Suppl 1):2-10.

20. Dvorak HF: Vascular permeability factor/vascular endothelial growth factor: a critical cytokine in tumor angiogenesis and a potential target for diagnosis and therapy. J Clin Oncol 2002, 20(21):4368-4380.

21. Willett CG, Boucher Y, di Tomaso E, Duda DG, Munn LL, Tong RT, Chung DC, Sahani DV, Kalva SP, Kozin SV, Mino M, Cohen KS, Scadden DT, Hartford AC, Fischman AJ, Clark JW, Ryan DP, Zhu AX, Blaszkowsky LS, Chen HX, Shellito PC, Lauwers GY, Jain RK: Direct evidence that the VEGF-specific antibody bevacizumab has antivascular effects in human rectal cancer. Nat Med 2004, 10(2):145-147.

22. Ranpura V, Hapani S, Wu S: Treatment-related mortality with bevacizumab in cancer patients: a meta-analysis. JAMA 2011, 305(5):487-494.

23. Rödel C, Arnold D, Hipp M, Liersch T, Dellas K, lesalnieks I, Hermann RM, Lordick F, Hinke A, Hohenberger W, Sauer R: Phase I-II trial of cetuximab, capecitabine, oxaliplatin, and radiotherapy as preoperative treatment in rectal cancer. Int J Radiat Oncol Biol Phys 2008, 70(4):1081-1086.

24. Rödel C, Liersch T, Hermann RM, Arnold D, Reese T, Hipp M, Fürst A, Schwella N, Bieker M, Hellmich G, Ewald H, Haier J, Lordick F, Flentje M, Sülberg H, Hohenberger W, Sauer R: Multicenter phase II trial of chemoradiation with oxaliplatin for rectal cancer. J Clin Oncol 2007, 25(1): 110-117.

25. Rödel C, Grabenbauer GG, Papadopoulos T, Hohenberger W, Schmoll HJ, Sauer R: Phase I/II Trial of Capecitabine, Oxaliplatin, and Radiation for Rectal Cancer. J Clin Oncol 2003, 16(21):3098-3104.

26. Dworak O, Keilholz L, Hoffmann A: Pathological features of rectal cancer after preoperative radiochemotherapy. Int J Colorectal Dis 1997, 12(1):19-23

27. Velenik V, Ocvirk J, Music M, Bracko M, Anderluh F, Oblak I, Edhemovic I, Brecelj E, Kropivnik M, Omejc M: Neoadjuvant capecitabine, radiotherapy, and bevacizumab (CRAB) in locally advanced rectal cancer: results of an open-label phase II study. Radiat Oncol 2011, 6:105.

28. Kennecke H, Berry S, Wong R, Zhou C, Tankel K, Easaw J, Rao S, Post J, Hay $\mathrm{J}$ : Pre-operative bevacizumab, capecitabine, oxaliplatin and radiation among patients with locally advanced or low rectal cancer: a phase II trial. Eur J Cancer 2012, 48(1):37-45

29. Dipetrillo T, Pricolo V, Lagares-Garcia J, Vrees M, Klipfel A, Cataldo T, Sikov W, McNulty B, Shipley J, Anderson E, Khurshid H, Oconnor B, Oldenburg NB, Radie-Keane K, Husain S, Safran H: Neoadjuvant bevacizumab, oxaliplatin, 5-fluorouracil, and radiation for rectal cancer. Int J Radiat Oncol Biol Phys 2012, 82(1):124-129.

30. Crane CH, Eng C, Feig BW, Das P, Skibber JM, Chang GJ, Wolff RA, Krishnan S, Hamilton S, Janjan NA, Maru DM, Ellis LM, Rodriguez-Bigas MA: Phase II trial of neoadjuvant bevacizumab, capecitabine, and radiotherapy for locally advanced rectal cancer. Int J Radiat Oncol Biol Phys 2010, 76(3):824-830.

31. Willett CG, Duda DG, Ancukiewicz M, Shah M, Czito BG, Bentley R, Poleski M, Fujita H, Lauwers GY, Carroll M, Tyler D, Mantyh C, Shellito P, Chung DC, Clark JW, Jain RK: A safety and survival analysis of neoadjuvant bevacizumab with standard chemoradiation in a phase I/II study compared with standard chemoradiation in locally advanced rectal cancer. Oncologist 2010, 15(8):845-851.

32. Willett CG, Duda DG, di Tomaso E, Boucher Y, Ancukiewicz M, Sahani DV, Lahdenranta J, Chung DC, Fischman AJ, Lauwers GY, Shellito P, Czito BG, Wong TZ, Paulson E, Poleski M, Vujaskovic Z, Bentley R, Chen HX, Clark JW, Jain RK: Efficacy, safety, and biomarkers of neoadjuvant bevacizumab, radiation therapy, and fluorouracil in rectal cancer: a multidisciplinary phase II study. J Clin Oncol 2009, 27(18):3020-3026.

33. Czito BG, Bendell JC, Willett CG, Morse MA, Blobe GC, Tyler DS, Thomas J, Ludwig KA, Mantyh CR, Ashton J, Yu D, Hurwitz HI: Bevacizumab, oxaliplatin, and capecitabine with radiation therapy in rectal cancer: Phase I trial results. Int J Radiat Oncol Biol Phys 2007, 68(2):472-478.

34. Winkler J, Zipp L, Knoblich J, Zimmermann F: Simultaneous neoadjuvant radiochemotherapy with capecitabine and oxaliplatin for locally 
advanced rectal cancer, Treatment outcome outside clinical trials. Strahlenther Onkol 2012, 188(5):377-382.

35. Ofner D, Devries AF, Schaberl-Moser R, Greil R, Rabl H, Tschmelitsch J, Zitt M, Kapp KS, Fastner G, Keil F, Eisterer W, Jäger R, Offner F, Gnant M, Thaler J: TAKO 05/ABCSG R-02 Trial Investigators. Preoperative oxaliplatin, capecitabine, and external beam radiotherapy in patients with newly diagnosed, primary operable, $\mathrm{CT}_{3} \mathrm{NxM0}$, low rectal cancer: a phase II study. Strahlenther Onkol 2011, 187(2):100-107.

36. Blazer DG 3rd, Kishi Y, Maru DM, Kopetz S, Chun YS, Overman MJ, Fogelman D, Eng C, Chang DZ, Wang H, Zorzi D, Ribero D, Ellis LM, Glover KY, Wolff RA, Curley SA, Abdalla EK, Vauthey JN: Pathologic response to preoperative chemotherapy: a new outcome end point after resection of hepatic colorectal metastases. J Clin Oncol 2008, 26(33):5344-5351.

37. Kishi Y, Zorzi D, Contreras CM, Maru DM, Kopetz S, Ribero D, Motta M, Ravarino N, Risio M, Curley SA, Abdalla EK, Capussotti L, Vauthey JN: Extended preoperative chemotherapy does not improve pathologic response and increases postoperative liver insufficiency after hepatic resection for colorectal liver metastases. Ann Surg Oncol 2010, 17(11): 2870-2876.

38. Ribero D, Wang H, Donadon M, Zorzi D, Thomas MB, Eng C, Chang DZ, Curley SA, Abdalla EK, Ellis LM, Vauthey JN: Bevacizumab improves pathologic response and protects against hepatic injury in patients treated with oxaliplatin-based chemotherapy for colorectal liver metastases. Cancer 2007, 110(12):2761-2767.

39. Klinger M, Tamandl D, Eipeldauer S, Hacker S, Herberger B, Kaczirek K, Dorfmeister M, Gruenberger B, Gruenberger T: Bevacizumab improves pathological response of colorectal cancer liver metastases treated with XELOX/FOLFOX. Ann Surg Oncol 2010, 17(8):2059-2065.

40. Bear HD, Tang G, Rastogi P, Geyer CE, Robidoux A, Atkins JN, Baez L, Brufsky A, Mehta RS, Fehrenbacher L, Pajon ER, Senecal FM, Gaur R, Margolese RG, Adams PT, Gross HM, Swain SM, Mamounas EP, Costantino JP, Wolmark N: The effect on $\mathrm{pCR}$ of bevacizumab and/or antimetabolites added to standard neoadjuvant chemotherapy: NSABP protocol B-40. J Clin Oncol 2011, 29:ASCO 2011. suppl; abstr LBA1005.

41. von Minckwitz G, Eidtmann H, Rezai M, Fasching PA, Tesch H, Eggemann H, Schrader I, Kittel K, Hanusch C, Kreienberg R, Solbach C, Gerber B, Jackisch C, Kunz G, Blohmer JU, Huober J, Hauschild M, Fehm T, Müller BM, Denkert C, Loibl S, Nekljudova V, Untch M: German Breast Group; Arbeitsgemeinschaft Gynäkologische Onkologie-Breast Study Groups. Neoadjuvant chemotherapy and bevacizumab for HER2-negative breast cancer. N Engl J Med 2012, 366(4):299-309.

42. Allegra CJ, Yothers G, O'Connell MJ, Sharif S, Petrelli NJ, Colangelo LH, Atkins JN, Seay TE, Fehrenbacher L, Goldberg RM, O'Reilly S, Chu L, Azar CA, Lopa S, Wolmark N: Phase III trial assessing bevacizumab in stages II and III carcinoma of the colon: results of NSABP protocol C-08. J Clin Oncol 2011, 29(1):11-16.

43. de Gramont A, Van Cutsem E, Schmoll HJ, Tabernero J, Clarke S, Moore MJ, Cunningham D, Cartwright TH, Hecht JR, Rivera F, Im SA, Bodoky G, Salazar R, Maindrault-Goebel F, Shacham-Shmueli E, Bajetta E, Makrutzki M, Shang A, André T, Hoff PM: Bevacizumab plus oxaliplatin-based chemotherapy as adjuvant treatment for colon cancer (AVANT): a phase 3 randomised controlled trial. Lancet Oncol 2012, 13(12):1225-1233.

44. Dewdney A, Cunningham D, Tabernero J, Capdevila J, Glimelius B, Cervantes A, Tait D, Brown G, Wotherspoon A, Gonzalez De Castro D, Chua YJ, Wong R, Barbachano Y, Oates J, Chau I: Multicenter randomized phase II clinical trial comparing neoadjuvant oxaliplatin, capecitabine, and preoperative radiotherapy with or without cetuximab followed by total mesorectal excision in patients with high-risk rectal cancer (EXPERT-C). J Clin Oncol 2012, 30(14):1620-1627.

doi:10.1186/1748-717X-8-90

Cite this article as: Dellas et al: Phase II trial of preoperative radiochemotherapy with concurrent bevacizumab, capecitabine and oxaliplatin in patients with locally advanced rectal cancer. Radiation Oncology 2013 8:90.

\section{Submit your next manuscript to BioMed Central and take full advantage of:}

- Convenient online submission

- Thorough peer review

- No space constraints or color figure charges

- Immediate publication on acceptance

- Inclusion in PubMed, CAS, Scopus and Google Scholar

- Research which is freely available for redistribution

Submit your manuscript at www.biomedcentral.com/submit
C Biomed Central 